\title{
Integrated management systems based on risk assessment: Methodology development and case studies
}

\author{
Vulanović, S. ${ }^{a}$, Delić, M. ${ }^{\text {a, }}$, Kamberović, B. ${ }^{a}$, Beker, I. ${ }^{a}$, Lalić, B. ${ }^{a}$ \\ ${ }^{\mathrm{a}}$ Faculty of Technical Sciences, University of Novi Sad, Novi Sad, Serbia
}

\begin{abstract}
A B S T R A C T
The implementation of management systems in organizations is often based on a "blind" meeting of requirements set by the selected standard, while these requirements are not in direct relation to the risks of the organizations. Therefore, it often happens that the established management system is not operational or is not aligned with the context and real needs of the organization. This paper presents general model for the design of an integrated management system based on risk assessment of organization's processes. The model was based on the primary hypothesis that a process that has a higher risk should be described in more detail in order to be adequately realized. The presented Model was tested on three diverse companies which had already implemented management systems according to international standards. Comparing the existing with the projected documentation in three companies, it was concluded that the number, scope and structure of documented information were optimized for successful risk management, which lowers the overall costs and enables efficient management of the company. The paper provides scientific approach and methodology for designing the integrated management system in any organization, using existing risks as universal integrating factor.
\end{abstract}

\section{ARTICLE INFO}

Keywords:

Integrated management system;

Risk management;

Process approach;

Failure mode effect analysis

(FMEA)

*Corresponding author:

delic@uns.ac.rs

(Delić, M.)

Article history:

Received 13 February 2019

Revised 13 September 2019

Accepted 16 September 2019

(C) 2020 CPE, University of Maribor. All rights reserved.

\section{References}

[1] Beckmerhagen, I.A., Berg, H.P., Karapetrovic, S.V., Willborn, W.O. (2003). Integration of management systems: Focus on safety in the nuclear industry, International Journal of Quality \& Reliability Management, Vol. 20, No. 2, 210-228, doi: 10.1108/02656710310456626.

[2] Rebelo, M., Santos, G., Silva, R. (2013). Conception of a flexible integrator and lean model for integrated management systems, Total Quality Management \& Business Excellence, Vol. 25, No. 5-6, 683-701, doi: 10.1080/ 14783363.2013 .835616$.

[3] Bekčić, S., Kelečević, N., Marinković, V., Tasic, L., Krajnovic, D. (2013). Approach to the integration of management systems in a pharmaceutical organization, Indian Journal of Pharmaceutical Education and Research, Vol. 47, Vol. 3, 19-25.

[4] Domingues, J.P.T., Sampaio, P., Arezes, P.M. (2015). Analysis of integrated management systems from various perspectives, Total Quality Management \& Business Excellence, Vol 26, No. 11-12, 1311-1334, doi: 10.1080/ 14783363.2014 .931064$.

[5] International Organization for Standardization, ISO 31000: 2009 Risk management - Guidelines on principles and implementation of risk management, ISO Copyright Office, Geneva.

[6] Pojasek, R.B. (2006). Is your integrated management system really integrated?, Environmental Quality Management, Vol. 16, No. 2, 89-97, doi: 10.1002/tqem.20124.

[7] Wilkinson, G., Dale, B.G. (2006). Integrated management systems: A model based on a total quality approach, Managing Service Quality: An International Journal, Vol. 11, No. 5, 318-330, doi: 10.1108/09604520110404040. 
[8] Zeng, S.X., Shi, J.J., Lou, G.X. (2007). A synergetic model for implementing an integrated management system: An empirical study in China, Journal of Cleaner Production, Vol. 15, No. 18, 1760-1767, doi: 10.1016/i.jclepro. 2006.03.007.

[9] Zwetsloot, G.I.J.M. (1995). Improving cleaner production by integration into the management of quality, environment and working conditions, Journal of Cleaner Production, Vol. 3, No. 1-2, 61-66, doi: 10.1016/09596526(95)00046-H.

[10] Jørgensen, T.H., Remmen, A., Mellado, M.D. (2006). Integrated management systems - Three different levels of integration, Journal of Cleaner Production, Vol. 14, No, 8, 713-722, doi: 10.1016/i.jclepro.2005.04.005.

[11] British Standard Institute (BSI), (2012). PAS 99 Specification of common management systems requirements as a framework for integration, BSI Copyright Office, London.

[12] Karapetrovic, S., Willborn, W. (1998). Integration of quality and environmental management systems, The TQM Magazine, Vol. 10, No. 3, 204-213, doi: 10.1108/09544789810214800.

[13] Karapetrovic, S. (2002). Strategies for the integration of management systems and standards, The TQM Magazine, Vol. 14, No, 1, 61-67, doi: 10.1108/09544780210414254.

[14] Labodová, A. (2004). Implementing integrated management systems using a risk analysis based approach, Journal of Cleaner Production, Vol. 12, No. 6, 571-580, doi: 10.1016/i.jclepro.2003.08.008.

[15] Salomone, R. (2008). Integrated management systems: Experiences in Italian organizations, Journal of Cleaner Production, Vol. 16, No. 16, 1786-1806, doi: 10.1016/i.jclepro.2007.12.003.

[16] Asif, M., Fisscher, O.A.M., De Bruijn, E.J., Pagell, M. (2010). An examination of strategies employed for the integration of management systems, The TQM Journal, Vol. 22, No. 6, 648-669, doi: 10.1108/1754273101108 $\underline{5320}$.

[17] Bernardo, M., Casadesus, M., Karapetrovic, S., Heras, I. (2009). How integrated are environmental, quality and other standardized management systems? An empirical study, Journal of Cleaner Production, Vol. 17, No. 8, 742750, doi: 10.1016/j.jclepro.2008.11.003.

[18] Bernardo, M., Casadesus, M., Karapetrovic, S., Heras, I. (2012). Do integration difficulties influence management system integration levels?, Journal of Cleaner Production, Vol. 21, No. 1, 23-33, doi: 10.1016/i.jclepro.2011. 09.008.

[19] Asif, M., De Bruijn, E.J., Fisscher, O.A.M., Searcy, C. (2010). Meta-management of integration of management systems. The TQM Journal, Vol. 22, No. 6, 570-582, doi: 10.1108/17542731011085285.

[20] Mežinska, I., Lapina, I., Mazais, J. (2015). Integrated management systems towards sustainable and socially responsible organisation, Vol. 26, No. 5-6, 469-481, doi: 10.1080/14783363.2013.835899.

[21] International Organization for Standardization (ISO), (2009). ISO 31010:2009 - Risk management - Risk assessment techniques, ISO Copyright Office, Geneva.

[22] McDermott, R.E., Mikulak, R.J., Beauregard, M.R. (2008). The basics of FMEA, Second edition, CRC Press, Taylor \& Francis Group, New York, USA.

[23] Vulanović, S., Beker, I., Radlovački, V., Delić, M. (2012). The appliance of work flow diagram as a tool for identification and grouping of failures in processes of integrated management system, International Journal Advanced Quality, Vol. 40, No. 1, 23-26.

[24] Banduka, N., Veža, I., Bilić, B. (2016). An integrated lean approach to process failure mode and effect analysis (PFMEA): A case study from automotive industry, Advances in Production Engineering \& Management, Vol. 11, No. 4, 355-365, doi: 10.14743/apem2016.4.233.

[25] Sankar, N.R., Prabhu, B.S. (2001). Modified approach for prioritization of failures in a system failure mode and effects analysis, International Journal of Quality \& Reliability Management, Vol. 18, No. 3, 324-336, doi: 10.1108/ $\underline{02656710110383737 .}$

[26] International Organization for Standardization (ISO), (2001). ISO/TR 10013:2001 Guidelines for quality management system documentation, ISO Copyright Office, Geneva.

[27] Delić, M., Radlovački, V., Kamberović, B., Maksimović, R., Pečujlija, M. (2013). Examining relationships between quality management and organisational performance in transitional economies, Total Quality Management \& Business Excellence, Vol. 25, No. 3-4, 367-382, doi: 10.1080/14783363.2013.799331. 


\section{APEM}

\title{
Integrirani sistemi upravljanja, ki temeljijo na oceni tveganja: Razvoj metodologije in študije primerov
}

\author{
Vulanović, S. ${ }^{a}$, Delić, M. ${ }^{\text {a, }}$, Kamberović, B. ${ }^{a}$, Beker, I. ${ }^{a}$, Lalić, B. ${ }^{a}$ \\ ${ }^{\mathrm{a}}$ Faculty of Technical Sciences, University of Novi Sad, Novi Sad, Serbia
}

\section{POVZETEK}

Izvajanje sistemov upravljanja v organizacijah pogosto temelji na "slepem" izpolnjevanju zahtev, ki jih določa izbrani standard, medtem ko te zahteve niso neposredno povezane s tveganji organizacij. Zato se pogosto zgodi, da vzpostavljen sistem upravljanja ne deluje ali ni usklajen s kontekstom in dejanskimi potrebami organizacije. $V$ prispevku je predstavljen splošni model za zasnovo integriranega sistema vodenja, ki temelji na oceni tveganja procesov organizacije. Model temelji na primarni hipotezi, da je treba postopek, ki ima večje tveganje, podrobneje opisati, da ga bomo lahko ustrezno uresničili. Predstavljeni model je bil preizkušen na treh različnih podjetjih, ki so že uvedla sisteme vodenja po mednarodnih standardih. V primerjavi obstoječe in predvidene dokumentacije $v$ treh podjetjih smo ugotovili, da so število, obseg in struktura dokumentiranih informacij optimizirani za uspešno obvladovanje tveganj, kar znižuje skupne stroške in omogoča učinkovito upravljanje podjetja. Prispevek podaja znanstveni pristop in metodologijo za oblikovanje integriranega sistema upravljanja v organizaciji $\mathrm{z}$ uporabo obstoječih tveganj kot univerzalnega dejavnika povezovanja.

\section{PODATKI O ČLANKU}

\section{Ključne besede:}

Integrirani sistem upravljanja; Upravljanje s tveganji;

Procesni pristop;

Analiza učinka načina okvare (FMEA)

*Kontaktna oseba: delic@uns.ac.rs (Delić, M.)

Zgodovina članka:

Prejet 13. februarja 2019

Popravljen 13. septembra 2019

Sprejet 16. septembra 2019 